\title{
Numerical Simulation on the Die Casting Forming Process of a Magnesium Alloy Bearing Block
}

\author{
Hanwu Liu ${ }^{a}$, Huihui Sun ${ }^{b}$, Junming Liu $^{c}$, Zhiping Zhang \\ School of Mechanical and Electrical Engineering, North China Institute of Science and Technology, \\ Sanhe, Hebei, 065201, China \\ ahanwu-liu@sohu.com, ${ }^{\text {b5 }}$ $49017154 @ q q . c o m$, 'liujunming@ncist.edu.cn
} Keywords: Thermal Equilibrium; Filling Process; Solidification; Die Casting; Temperature Field;
Shrinkage and Porosity

\begin{abstract}
Magnesium alloy has the great advantage of aluminum compared to other light alloy materials, so magnesium alloy is being carried out step by step in automotive applications and attracted attention of the automobile industry because of superior characteristics of recirculation replace previous material work, and achieved obvious effect of lightweight. With the aid of PRE/ENGINEER software, the 3D solid modeling of YM5 magnesium alloy vehicle bearing base is carried out in this paper. After determining the YM5 magnesium alloy die casting technology parameters, simulate the grids were generated using the casting simulation software ProCAST file, the numerical simulation of filling and solidification process for parts to carry on respectively, and the parts of the distribution of temperature field and the possible defects is get. Analyze the different pouring temperature $\left(640^{\circ} \mathrm{C}, 630^{\circ} \mathrm{C}, 615^{\circ} \mathrm{C}, 600^{\circ} \mathrm{C}\right)$ influence on solidification process defects, and optimizing the pouring system, improving the quality of castings, in order to achieve before actual production to reduce or avoid the production of casting defects, which provide technical support for producing the similar products.
\end{abstract}

\section{Introduction}

Bearing seat is a component which is used to support the bearing on the base of steam turbine cylinder. With the rapid development of modern automobile industry, the development of magnesium alloy die casting production equipment and the mature of die casting process, the requirement and application of magnesium alloy die casting will be more extensive. Due to the requirement of energy saving, environmental protection and lightweight, the application of magnesium alloy in automobile has attracted more and more attention of the automobile industry. However, magnesium alloy die-casting process, liquid metal in the high speed filling cavity, prone to pores and inclusions, making it difficult to be welded or components for air tightness requirements higher, due to lead to porosity defects in castings can not be heat treated, the mechanics to further improve the performance severely limits the magnesium alloy in automobile further applications, especially for complex applications of casting of magnesium alloy.

At the same time, because of the character of the process of die casting process, casting microstructure exist coarse dendrite, from the surface to the core there are two defect bands and die casting process on casting microstructure, defect formation and mechanical properties is significantly affected. Therefore, the research of magnesium alloy die casting technology and simulation technology to develop the application of magnesium alloy structure is one of the research directions in the research of magnesium alloy.

In this paper, a car with a magnesium alloy bearing seat as the research object, using Pro / E software to establish the mathematical model, using professional casting simulation software ProCAST for cars with magnesium alloy bearing seat of mold filling process of liquid metal flow, temperature field distribution was numerically simulated to predict the possible loose, cold insulation and misrun defects, and to analyze the influence of die casting process parameters on the forming process. 


\section{Design of the bearing pedestal mathematical modeling and casting system based on Pro/E}

The experimental casting material uses YM5 (YZMgA19Zn), its chemical composition as shown in Table 1

Table 1 Chemical composition of YM5

\begin{tabular}{cccccccc}
\hline $\mathrm{Al}$ & $\mathrm{Zn}$ & $\mathrm{Mn}$ & $\mathrm{Fe}$ & $\mathrm{Cu}$ & $\mathrm{Si}$ & $\mathrm{Ni}$ & $\mathrm{Mg}$ \\
\hline $7.5 \sim 9.5$ & $0.2 \sim 0.8$ & $\leqslant 0.50$ & 0.08 & 0.10 & 0.25 & 0.01 & allowance \\
\hline
\end{tabular}

According to the parts of the three view the use of Pro/E parts module to establish the bearing block model. According to the design requirements of the die casting die and the characteristics of the die casting process, the casting system is designed as shown in Fig. 1. The mould use one module and two pieces of die casting.

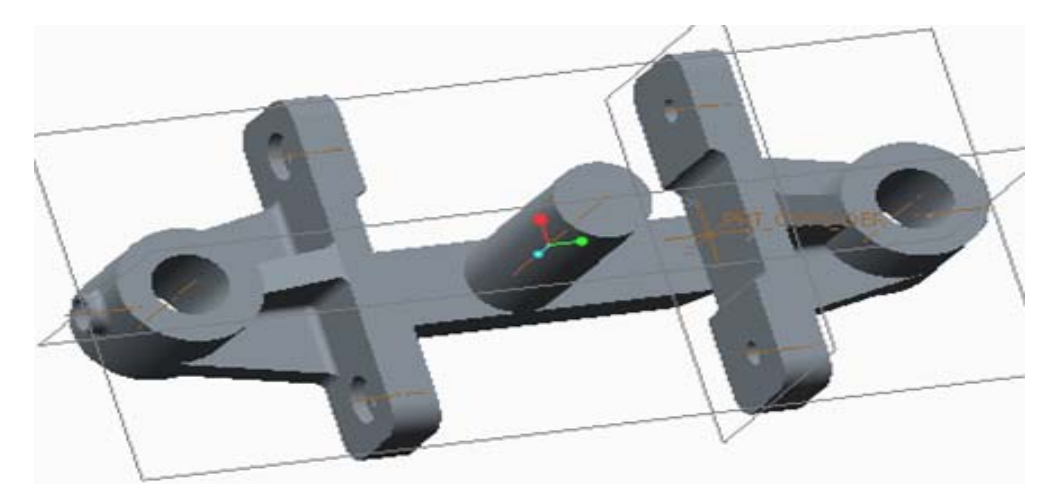

Fig. 1 Gating system

\section{Thermal equilibrium analysis of the Magnesium Alloy bearing block based on ProCAST}

Die casting quality and production efficiency in a large extent depends on the heat balance of the die casting die, so in the flow field of die casting, temperature field simulation before the first heat balance analysis, find the thermal balance of mold temperature, the thermal equilibrium temperature directly into the temperature field and flow field analysis for initial conditions, will be more accurate, more reasonable simulation results.

Fig. 2 is the thermal equilibrium analysis of magnesium alloy bearing block. Fig. 2 shows, in three times before the circulation of the mold and the casting temperature gradient change is particularly evident, fluctuated greatly. The reason is that the temperature distribution in the die did not reach the state of stable production, after 7 cycles after the mold temperature distribution gradually achieve a state of steady production of the thermal equilibrium state. Overall, the change trend of temperature curve consistent, each cycle began to die is in casting out not the cooling stage and direct production of the next cycle, the mold temperature rise, high temperature, and casting temperature gradient decreases. At the end of the tenth cycle, the equilibrium state is reached, at which the mold temperature is about $266^{\circ} \mathrm{C}$. 


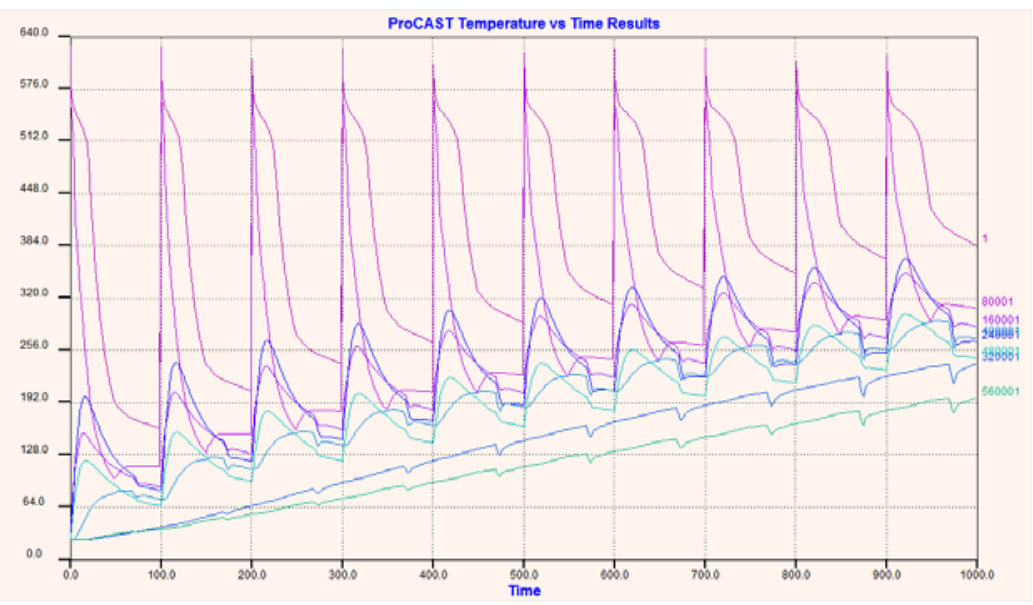

Fig. 2 Thermal equilibrium analysis of die casting

\section{The coupled flow and temperature field simulation of bearing seat type process}

There are two kinds of coupling methods of flow field and temperature field in the process of solidification and filling. One method is the direct coupling which need more accurate and more consumption of CPU time; the second method is the indirect method, that is, the superposition of multi field calculation, the method is fast, but the result will be a certain error. The first method is used in this simulation. Simulation results of the coupling of flow field and temperature field in filling process are shown in Fig. 3.

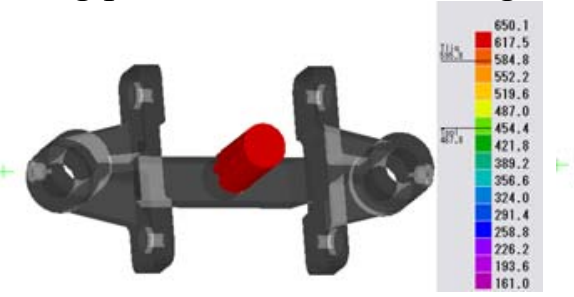

$\mathrm{Step}=10$

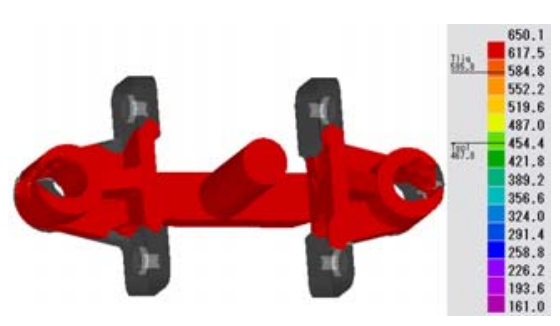

Step $=70$

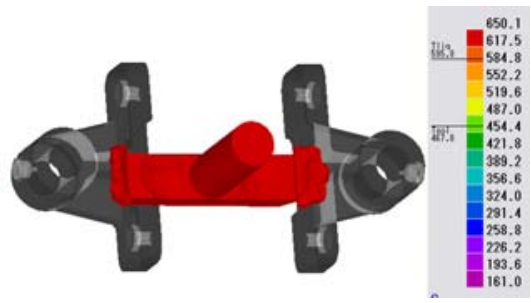

Step $=30$

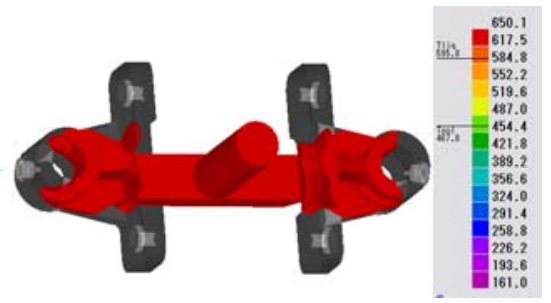

Step $=50$

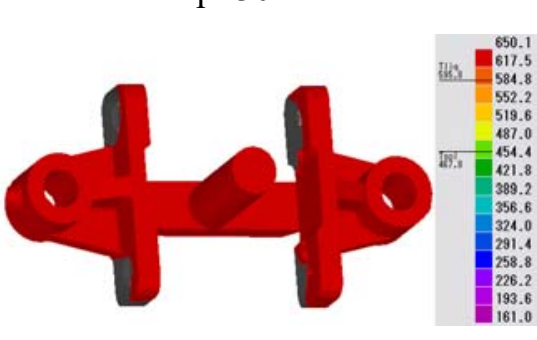

Step $=90$

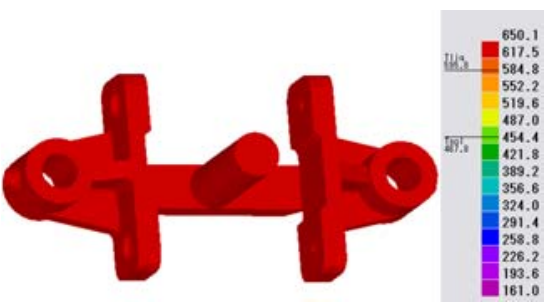

Step $=110$

Fig. 3 Coupling simulation results of flow field and temperature field in filling process

Fig. 3 can be seen at the beginning of the filling and casting liquid flows through the runner to the gate, the ingate sectional area decreases, increased speed, fast charging into type cavity. After filling in the casting mould cavity, the casting liquid impact to the cavity wall at a certain angle, and then fill the other parts along the cavity wall. When the STEP=40 is in, the casting solution meets the small core to start the separation. At this time, it is easy to form eddy current, gas and other defects, but this time the filling type does not happen. Then the casting liquid continues to flow along the cavity wall, the rapid filling cavity, in $\mathrm{STEP}=110$, complete the filling of the casting, filling the cavity is completely filled, there is no lack of casting defects.

The change of temperature field in solidification process is shown in Fig. 4. From Fig. 4 can be seen that the castings to be fully solidified, but thick wall at the center part of the solidification rate is slow, resulting in wall thickness at the center part of liquid metal during solidification is not from around the cast liquid feeding, here is easy to form shrinkage and holes. This phenomenon has also 
been in Fig. $4 \mathrm{x}$ direction section of thick walled casting at solid near the liquidus temperature field distribution proved, the map can be seen, thick walled center at ambient temperature before the center to solidus, the solidification of the prior to the center.

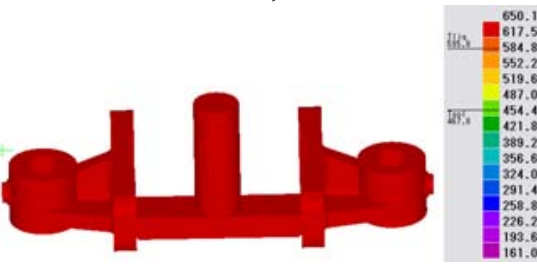

Step $=120$

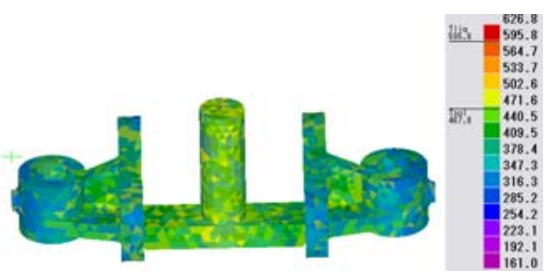

Step $=150$

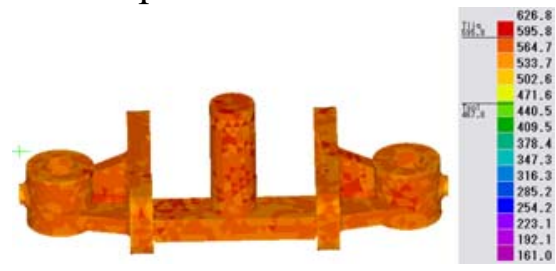

Step $=230$

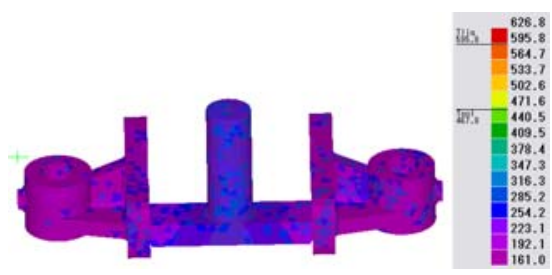

Step $=160$

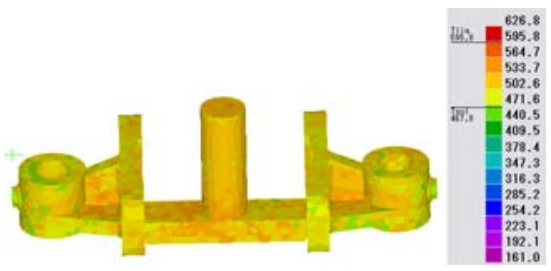

Step $=140$

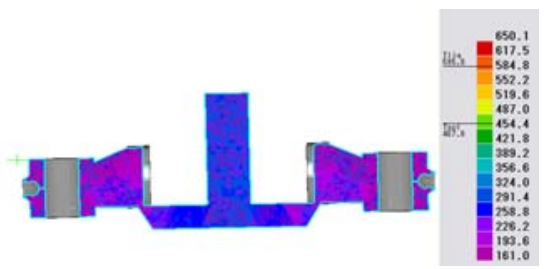

$\mathrm{X}$ direction slice

Fig. 4 Temperature changes of field during solidification

\section{Observation and analysis of the calculation results of shrinkage and porosity}

ProCAST can confirm the position of the sealing liquid. Use special criterion, such as the criterion of macroscopic shrinkage or Niyama criterion to determine whether the porosity shrinkage will occur in the sensitive area. At the same time, ProCAST can calculate the length of shrinkage and shrinkage. In die casting simulation, ProCAST can accurately calculate the size and position of the hot section, the cooling and heating channel, and the position of the overflow port.

The shrinkage and porosity are cast in the cooling process of internal compensation caused by lack of cavities. The main reasons are pouring temperature is too high, low pressure injection ratio, casting in the structure of wall thickness change, the thickness of the inner gate is too small, the metal liquid filling time is too short, etc.. From these reasons, we can see that in addition to the casting wall thickness of the structure change greatly, other reasons can be attributed to the rationality of the casting parameters, from Fig. 4 shows, in gate for casting will prior to casting solidification, even if the increase of injection than the pressure within the gate velocity shrinkage hole defects also don't get great improvement, and pouring temperature is too high will cause casting liquid cooling contraction quantity increases, thereby increasing the shrinkage cavity defects. In this regard, it is effective to reduce the shrinkage and porosity in the pouring temperature range. 


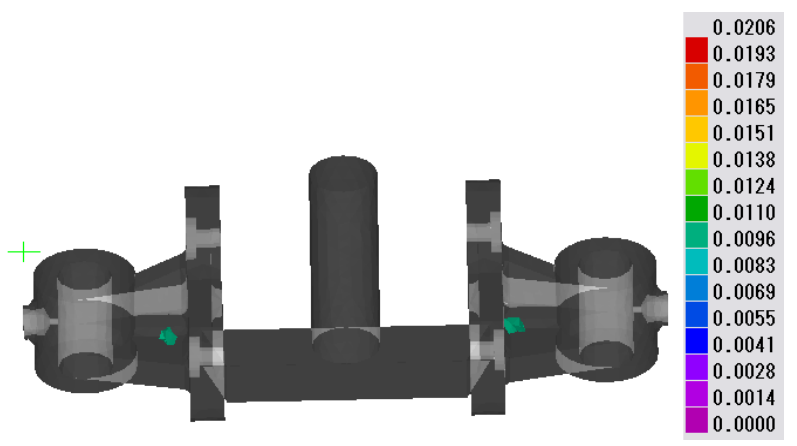

Temperature $=640{ }^{\circ} \mathrm{C}$

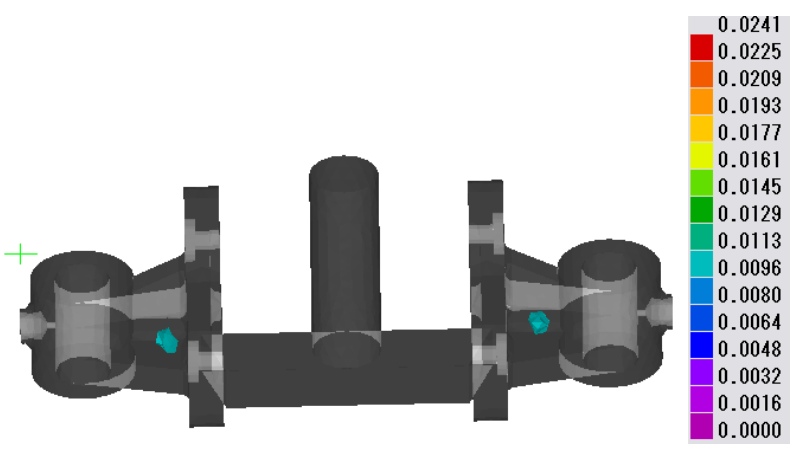

Temperature $=615^{\circ} \mathrm{C}$

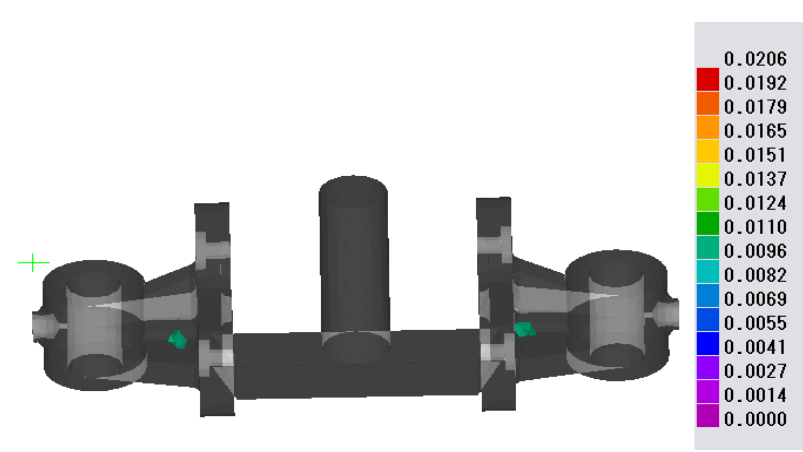

Temperature $=630{ }^{\circ} \mathrm{C}$

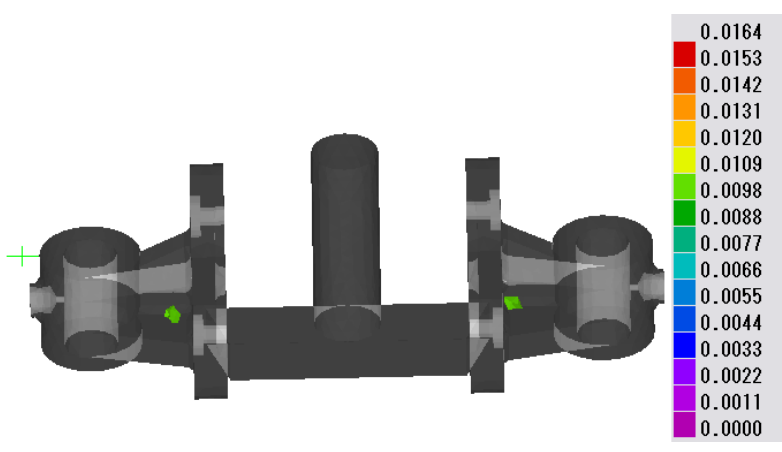

Temperature $=600{ }^{\circ} \mathrm{C}$

Fig. 5 Shrinkage and porosity produced at different temperatures

On the basis of finite element simulation, without changing other parameters, the pouring temperature is changed to $640^{\circ} \mathrm{C}, 630^{\circ} \mathrm{C}, 615^{\circ} \mathrm{C}, 600^{\circ} \mathrm{C}$, and the simulation results are shown in Fig. 5. In Fig. 5, the pouring temperature is $640^{\circ} \mathrm{C}$, shrinkage porosity, shrinkage decreased significantly; pouring temperature of $630^{\circ} \mathrm{C}$, shrinkage porosity, shrinkage than 640 Deg. $\mathrm{C}$ changed little; pouring temperature of $615^{\circ} \mathrm{C}$, shrinkage porosity, shrinkage hole area significantly larger; pouring temperature is up to $600{ }^{\circ} \mathrm{C}$, shrinkage porosity, shrinkage pore volume was significantly larger, compared to $650^{\circ} \mathrm{C}$ when similar. It can be known as the best pouring temperature of $630^{\circ} \mathrm{C}$ Celsius to $640^{\circ} \mathrm{C}$ Celsius. It is also known that in a certain range, the pouring temperature can reduce the shrinkage porosity and shrinkage porosity.

Lowering the pouring temperature can decrease the shrinkage porosity and shrinkage cavity, but there are still a lot of shrinkage porosity and shrinkage cavity were observed in Fig. 5 shrinkage position combined with Fig. $4 \mathrm{x}$ direction section of wall thickness of the slice graph of temperature field, can be found in the shrink loose cannot eliminate the reason is casting wall thickness of the structure changes. Due to the solidification characteristics of the pressure casting is from the outside cooling, when the casting wall thickness is larger, the internal inevitable shrinkage porosity problem. So, in terms of die casting, especially on the larger wall thickness of die casting, the existence of shrinkage, shrinkage problem is inevitable. In order to solve this problem, the following two schemes are proposed.

(1) Shorten the distance between the straight runner, the runner and the inner runner and the casting to reduce the heat loss, which can ensure the solidification of the runner and the die casting, so as to satisfy the principle of sequential solidification.

(2) Add the cooling system in the die casting die, to accelerate the wall thickness of the cooling rate, so as to achieve the order of solidification.

\section{Conclusion}

In this paper, based on the finite element method of the casting simulation software ProCAST to automobile bearing base casting heat balance simulation, and on the heat balance principle, the bearing type charger and solidification process numerical simulation, we get the distribution of the 
mold filling process flow and solidification temperature field, and the casting shrinkage porosity and shrinkage cavity defect formation was analyzed and improved, the conclusions are as follow:

(1) From the bearing seat die casting die thermal balance temperature curve can be seen, after ten cycles, the mold has basically reached the heat balance, the heat balance temperature is about 266 degrees.

(2) Though the treatment VieCAST can see the filling of the mold filling process in casting solution, can be accurate for design of die casting die for overflow launder of exhausting slot, the location of the design of provide the basis and avoid the designer by experience in the design of location and number of inaccurate, resulting in much waste or influencing the quality of castings.

(3) The temperature field simulation of the bearing block and the prediction of shrinkage porosity can be found out from ProCAST, and the defects of shrinkage cavity and shrinkage can be found in the wall thickness of the casting.

(4) Numerical simulation of different pouring temperatures can be found, the appropriate reduction of pouring temperature from 650 to 630 degrees $\mathrm{C}$ can reduce the shrinkage porosity, to improve the quality of castings.

(5) The further improvements of the analysis: in the establishment of the entity model should increase the overflow tank and exhaust slot, in order to achieve a more accurate simulation analysis.

\section{References}

[1] M.Lorenzo,J.M.Alegre and I.I.Cuesta. Magnesium alloy defectology AZ91D high pressure die cast and influence on the fatigue behavior. Fatigue \& Fracture of Engineering Materials\&Structures,2013(36).

[2] V.E.Bazhenov,A.V.Koltygin,A.V.Fadeev. The use of the ProCast software to simulate the process of investment casting of alloy based on Titanium Aluminide TNM-B1 into ceramic molds. Russian Journal of Non-Ferrous Metals, 2014,55(1).

[3] Jeong J H, Yang D Y. Application of an adaptive grid refinement technique to three-dimensional finite element analysis of the filling stage in the die-casting process. Journal of Material Processing Technology, 2001.111:59 63.

[4] Shepel Sergey V, Samuel Paolucci. Numerical simulation of filling and solidification of permanent model casting. Applied Thermal Engineering, 2002.22:229 248.

[5] Alkorta J, Gil Sevillano J. A comparison of FEM and upper-bound type analysis of equal-channel angular pressing (ECAP). Journal of Materials Processing Technology, 2003.141(3):313 318.

[6] Shojaei A, Ghaffarian S R, Karimian S M H. Simulation of the three-dimensional non-isothermal mold filling process in resin transfer molding. Composites science and technology, 2003.63:1931 1948.

[7] Sulaiman S, Hamouda A M S, Abedin S, et al. Simulation of metal filling progress during the casting progress. Journal of Material Processing Technology, 2000.100:224 22.

[8] M.Sadeghi and J .Mahmoudi. Experimental and Theoretical Studies on the Effect of Die Temperature on the Quality of the Products in High-Pressure Die-Casting Process. Advances in Materials Science and Engineering,2012.

[9] Zhenshan Zhang, Ruitian Zhang, Minggang Shen,etc. Study on Optimization of casting scheme for electrode. Casting technology, 2014(3). (In Chinese). 